\title{
UM LABORATÓRIO DIDÁTICO VIRTUAL DE FÍSICA PELA AMAZÔNIA
}

\author{
MÁrcio J. C. De SEnA ${ }^{1}$ Antônio Silas ${ }^{2}$ \\ RUBENS SILVA ${ }^{3}$ \\ ${ }^{1}$ Secretaria de Educação do Estado do Pará \\ ${ }^{2}$ Secretaria de Educação do Estado do Maranhão \\ ${ }^{3}$ Faculdade de Física, Universidade Federal do Pará, Belém, PA, Brasil
}

\begin{abstract}
Resumo
Nossa sociedade vive em constantes processos de evolução. Evolução que impulsiona mudanças no cotidiano proporcionadas por expressivos avanços tecnológicos. Por conseguinte, em se tratando do contexto educacional, essa evolução deve estar presente na prática educativa, sendo o professor o grande responsável pela inserção dessa nova realidade na escola. Logo, se os professores e alunos estão inseridos em um universo dinâmico em constante evolução, em contato com tecnologias cada vez mais avançadas, por que não introduzi-las dentro do contexto educacional? A realização de experimentos durante as aulas possui um papel importante para o ensino de Física, pois a preparação para o mundo do trabalho, das ciências e das tecnologias, em especial, em uma aula de Física com atividades experimentais, apresenta resultados significativos em relação ao aprendizado. Porém, os materiais utilizados no laboratório convencional nem sempre estão facilmente disponíveis em decorrência do custo muito elevado e do difícil acesso e manipulação dentro da realidade de cada escola. Nesta perspectiva, a criação de experimentos virtuais torna-se uma alternativa para o professor vencer esses desafios. Desafios estes em que o computador se apresenta como um fator motivador para o aluno, uma vez que, segundo Gaspar (2014), de acordo com a teoria de Vygotsky, para aprender, é necessário pensar e, para pensar a respeito de um problema, o aluno necessita de estímulos. Assim, o presente estudo tem como suporte os resultados de uma pesquisa-ação quali-quantitativa, realizada após a aplicação do produto, com contribuições diversas que visam facilitar o processo de ensino-aprendizagem de Física da teoria à prática.
\end{abstract}

Palavras-chave: Ensino de Física, Experimentos Virtuais, Ensino Médio. 


\begin{abstract}
Our society lives in constant processes of evolution. Evolution that gives rise to changes in our daily lives provided by significant technological advances. Therefore, in view of the educational context, this evolution must be present in the educational practice, being the teacher responsible for the insertion of this new reality into school. Then, if teachers and students are embedded in a dynamic universe in constant evolution, in contact with increasingly advanced technologies, why not to introduce them within the educational context? The realization of experiments during classes plays an important role in Physics teaching, once the preparation for the working world, sciences and technologies, and more specifically in a Physics class with experimental activities, presents significant results with respect to learning. However, materials used in conventional laboratories are not always readily available because of the very high cost and difficult access and manipulation under the reality of each school. In this perspective, the creation of virtual experiments becomes an alternative for teachers to overcome these challenges. Challenges in which the computer presents itself as a motivating factor for the student, since, according to Gaspar (2014) and Vygotsky's theory, to learn, it is necessary to think, and to think about a problem, the student needs stimuli. Thus, the present study is supported by the results of a qualitative and quantitative action research, carried out after the application of the product, with diverse contributions that aim to facilitate the teaching-learning process of Physics from theory to practice.
\end{abstract}

Keywords: Physics Teaching, Virtual Experiments, High School.

\title{
1 Introdução
}

Não é de hoje que o ensino das ciências, como um todo, permeia um campo complexo de saberes, os quais, historicamente, perpassam diferentes tendências pedagógicas, aliadas às grandes transformações vivenciadas pela humanidade. É neste contexto que as tendências pro-gressistas para o ensino de Física encontram alicerces em diferentes dispositivos nacionais, os quais têm por finalidade preparar o educando para o mundo do trabalho, das ciências e das tecnologias.

Dessa forma, a importância desta pesquisa se justifica pelo rompimento com as tendências liberais de ensino, baseadas em métodos tradicionais, reducionistas, com conteúdos desarticulados, descontextualizados e métodos estanques, direcionados, apenas, para provas e concursos, em detrimento do que propõem a Lei de Diretrizes e Bases da Educação Nacional - nº 9394/96 - as Diretrizes, Parâmetros Curriculares Nacionais e Orientações Curriculares Nacionais para o Ensino Médio, bem como ainda as Matrizes de Referências para o Exame Nacional de Ensino Médio, haja vista as mudanças epistemológicas que fundamentam a base curricular para o ensino em seu completo significado.

Logo, a pesquisa em torno do processo ensino-aprendizagem de Física é relevante para compreendermos a importância de se pensar não apenas o que deve ser alcançado como habilidades e competências, 


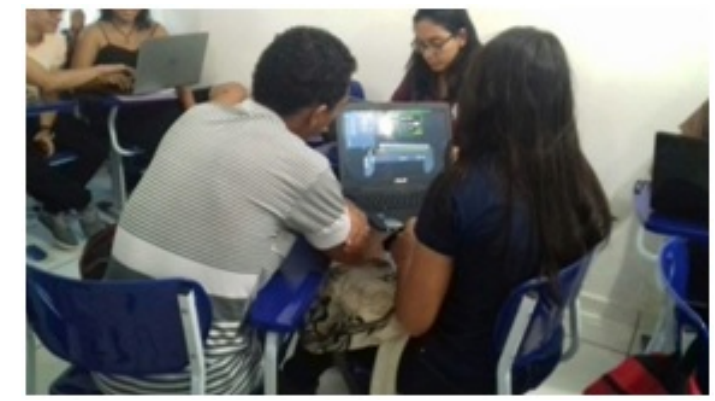

Figura 1: Laboratório Virtual sendo aplicado na rede pública em Tucuruí-PA. (Fonte: Arquivos do autor).

mas, essencialmente, como encontrar alternativas para formar um cidadão consciente, crítico, autônomo, participativo, engajado e politizado.

Nessa perspectiva, a pesquisa sobre a qual nos propomos parte da seguinte problemática: Quais os desafios e estratégias de se pensar o ensino de Física a partir de novas tendências pedagógicas? A partir desse questionamento, verifica-se a necessidade de incremento de novas práticas pedagógicas, buscando maior discussão entre docente e discente a respeito dos temas abordados. Assim, há que se destacar o teor dicotômico que fomenta o limiar que separa o ontem do hoje em educação, contrapondo o ensino de Física tradicional ao moderno, a partir da utilização de recursos pedagógicos inovadores, proporcionados pelas Tecnologias de Informação e Comunicação - TICs.

Na Figura 1, podemos observar a utilização do computador como auxiliador do ensino.

Por conseguinte, faz-se necessário um ensino de Física que prime por um aprender e ensinar muito além de procedimentos e regras. Para tal, o objetivo motivador é que o educador apresente a visão do que vem a ser a Física; do que constitui o ensino de Física; do que abrange a aprendizagem de Física, de como se articulam os agentes, ambientes e recursos que envolvem o processo de ensino-aprendizagem de Física, com uma proposta de contextualizar conceitos a partir da aplicação de um laboratório didático virtual de Física.

Portanto, visando aproximar os diferentes sujeitos do processo de ensino-aprendizagem, o presente estudo questiona ainda: Seria o laboratório virtual uma alternativa diante dos desafios que se abrem ao longo do processo de ensino-aprendizagem de Física?

Logo, para que a referida problemática seja investigada satisfatoriamente, traça-se como objetivos motivar os discentes; inserir a informática na prática docente; tornar a relação professor-aluno mais aberta, interativa; despertar, no docente, o interesse pela pesquisa; aguçar a curiosidade e contribuir para a compreensão dos alunos sobre os conteúdos abordados na teoria, mas pouco vivenciados na prática experimental.

A Figura 2 ilustra uma situação a respeito da trajetória para referenciais não inerciais. Simulação que auxilia a compreensão do aluno. 


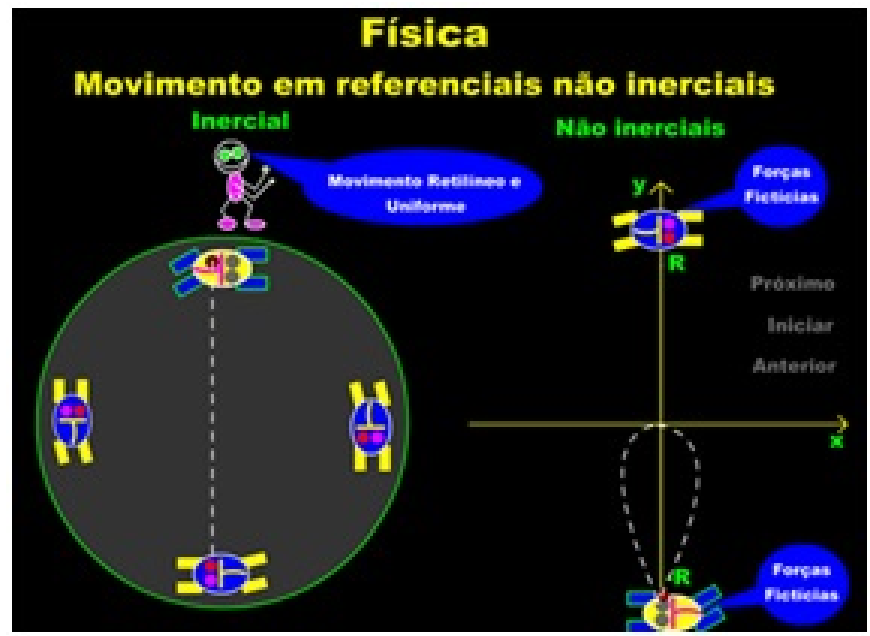

Figura 2: Laboratório virtual, experiência sobre formas de trajetória. (Fonte: Arquivos do autor).

Assim sendo, tornou-se necessária uma pesquisa de campo que apresentasse resultados capazes de validar ou não os questionamentos que se puseram sobre este estudo, no intuito de tentar circunscrever abordagens que abrangem um corpus muito mais amplo, complexo e diversificado. Ora, se de fato há algo que, certamente, está além da sala de aula, pode ser esta análise também um produtivo laboratório para se observar ocorrências diversas, já que possibilitaria mostrar que muito ainda pode ser feito ao longo do processo de ensino-aprendizagem inserido nas e pelas práticas sociais.

Nestes termos, se verdade é que os alunos apresentam grande dificuldade de aprendizagem dos conceitos da Física em consequência da aplicação de métodos tradicionais de ensino e da ausência de recursos pedagógicos modernos somados à carência de ferramentas metodológicas adequadas, o laboratório virtual pode ser uma alternativa eficaz para um ensino interativo, contextualizado, dinâmico e inovador, haja vista que professores e alunos estão, diariamente, em contato com tecnologias cada vez mais modernas. Nesse sentido, para Cavalcante (2008), o computador é um instrumento muito útil que auxilia o ensino e a aprendizagem de Física.

São necessários, portanto, métodos que permitam aos educandos sentirem-se inclusos em suas próprias aprendizagens e contextos, não apenas para que se possa chegar ao conhecimento de algo novo, no decorrer da prática pedagógica, enquanto prática educativa, mas, para que o aluno, dialeticamente, segundo Freire (1993), faça releituras, das circunstâncias já conhecidas e vivenciadas, como andar de bicicleta - ver Figura 3 - de modo a (re)construir-se como sujeito histórico e transformador. 


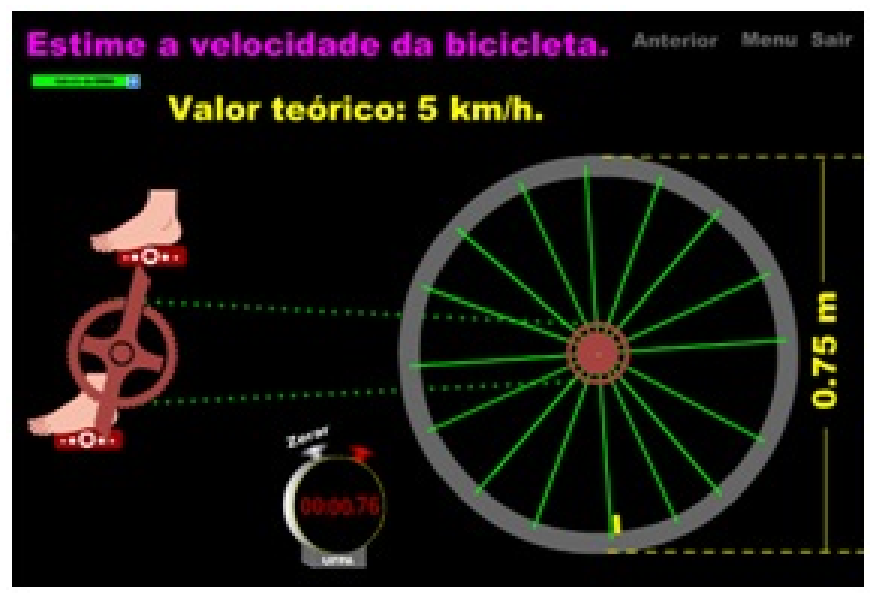

Figura 3: Laboratório didático virtual, experiência sobre movimento circunferencial uniforme (Fonte: Arquivos do autor).

Por isso, a realização de experimentos durante as aulas possui papel importante no pro-cesso ensino aprendizagem. Porém, nem sempre os professores conseguem introduzi-las dentro do contexto educacional, pois os materiais utilizados não são facilmente encontrados, algumas vezes tem um custo muito elevado e são de difíceis acessos e manipulação dentro da realidade de cada escola. É neste sentido que a criação de um laboratório virtual pode auxiliar o professor para vencer esses desafios.

Logo, ciente de que o processo de ensino-aprendizagem de Física incorpora elementos da ordem do social e do histórico, é o presente estudo de grande valia para criarmos situações em que tenhamos oportunidade de refletir sobre a prática docente como um todo, analisando, de forma contextualizada, o cotidiano da Física bem como ainda a física no cotidiano

\section{Justificativa para o uso de um Laboratório didático Virtual}

O grande avanço científico e tecnológico que a humanidade vive, principalmente a partir do início do século XX, transformou de maneira acelerada o modo como as pessoas se comunicam, trabalham, viajam, estudam e se divertem. Pessoas em diferentes continentes podem comunicar-se quase instantaneamente; o acesso ao conhecimento tornou-se mais democrático; as informações sobre um acontecimento, em qualquer lugar do mundo, são compartilhadas entre milhares de pessoas e se propagam por meio das redes sociais quase no mesmo instante em que o evento ocorre; as pessoas podem ter uma página na internet gratuitamente, expor suas opiniões e ler ideias alheias.

Por certo, há, assim, uma grande necessidade de aprender a trabalhar de maneira competente com um computador, seja com programas de elevado nível técnico para criar projetos das várias áreas das engenharias ou apenas escrever e enviar um email, pois celulares com múltiplas funções, tablets, computadores com capacidade de processamento e armazenamento cada vez maiores são produzidos, provocando uma grande e rápida evolução nas máquinas de maneira geral.

Destarte, se fato é que grandes transformações ocorreram e continuam modificando com rapidez a vida das pessoas, torna-se cada vez mais necessário o uso de tecnologias de informação e comunicação 


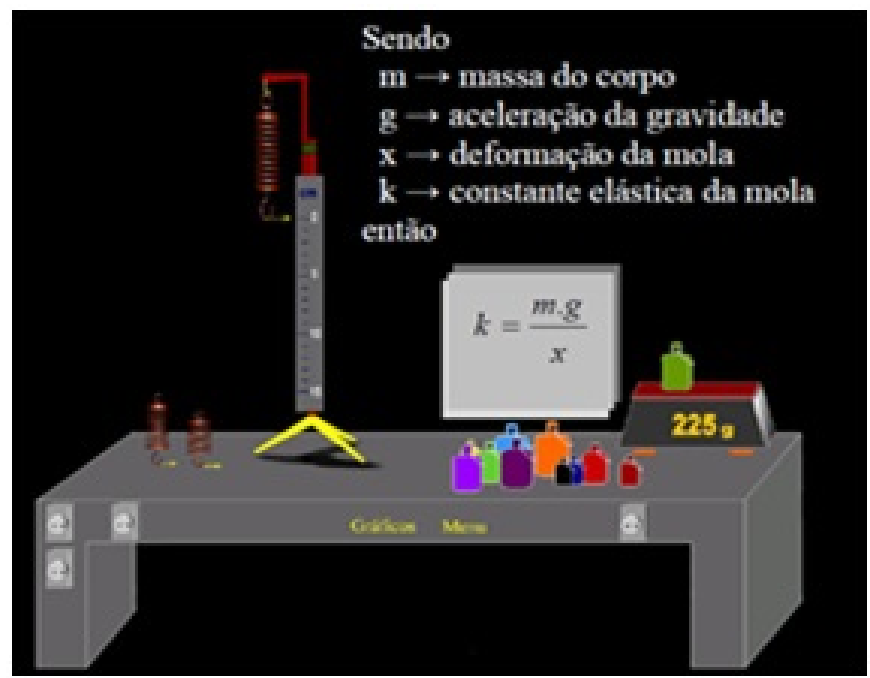

Figura 4: Laboratório didático virtual, experiência sobre lei de Hooke. (Fonte: Arquivos do autor).

dentro das salas de aula.

Em contrapartida, apesar dos contextos imprimirem novas tendências metodológicas, as práticas tradicionais de ensino continuam sendo a realidade da grande maioria das escolas. Logo, os resultados não poderiam ser outro: alunos desmotivados são encontrados frequentemente, sem interesse para transpor seus próprios limites e buscar novos conhecimentos.

Portanto, apesar dos avanços teóricos-metodológicos impulsionados por tendências pro-gressistas e modernas teorias de aprendizagem, ensinar Física, seja na educação básica ou no ensino superior, não tem sido tarefa fácil para os educadores. A maioria dos estudantes enxergam essa Ciência apenas como um aglomerado de fórmulas matemáticas e compreendem de maneira arbitrária o significado dos símbolos usados na linguagem matemática da descrição de modelos, leis, princípios e teorias da Física, sendo ainda comum professores usarem como único critério de avaliação da aprendizagem em Física a "habilidade" dos estudantes para escolher a fórmula correta, a mera substituição dos dados do problema e o cálculo da incógnita. Isso constitui características de uma aprendizagem mecânica, na qual o aprendiz não possui discer-nimento do que está calculando; dedica-se, apenas, a memorizar fórmulas sem entender o significado nem o contexto de validade de equações; busca, tão somente, resolver problemas sem nenhuma contextualização com o cotidiano dos estudantes.

Ao contrário, nossa proposta visa contribuir para um processo de ensino-aprendizagem além de procedimentos e regras. Para tal, apresentamos como produto um Laboratório Didático Virtual de Física para a educação básica, que estuda, por exemplo, a lei de Hooke de maneira mais interativa e dinâmica com a simulação computacional do experimento de Física (ver Figura 4) programados na linguagem Action Script 2.0 do Flash CS3 Macromedia [10] e publicados em formato executável para qualquer versão do Windows.

Assim, segundo Fiolhais \& Trindade (2003), as dificuldades que muitos alunos encontram na aprendizagem dos conteúdos de Física são conhecidas, por ser esta uma ciência de caráter experimental que apresenta diversos conceitos abstratos. Nestes termos, as razões para este insucesso justificam-se em 
decorrência da aplicação de métodos tradicionais de ensino, da ausência de meios pedagógicos modernos e da carência de ferramentas metodológicas mais adequadas.

Portanto, com o objetivo de propor alternativas eficazes para o ensino de Física, os PCNs (1999) e as novas Orientações Curriculares Nacionais para o Ensino Médio (2006) apontam a utilização da experimentação dentro do contexto escolar como alternativa. No entanto, se os custos para tal são demasiado altos, necessário é buscar outras alternativas que possam favorecer e facilitar o processo de ensino-aprendizagem de Física.

\section{O Flash CS3 Macromédia}

O Flash CS3 Macromedia, apesar de ter sido produzido, inicialmente, com o intuito de criar animações para páginas da web, mostra-se também extremamente útil para adaptar-se a programações Físicas e Matemáticas que aceitem a interação com o usuário, sendo, por meio desse diálogo, uma ferramenta potencialmente eficaz para produção de executáveis com animações para simular experiências de Física, ricas em detalhes, realismo, interatividade, não estáticas e que produzem um ambiente virtual cativante e ao mesmo tempo, podem reduzir o grau de abstração de fenômenos e conceitos físicos, contribuindo, desta maneira, para diminuir o esforço cognitivo do estudante durante a assimilação de novos conhecimentos de Física.

\section{Vantagens e limitações das simulações computacionais no ensino de física}

Parece ser consenso entre professores de Ciências, de modo geral, e de Física, em particular, que simulações computacionais elaboradas com qualidade e ricas em detalhes que mostrem animações de modelos simplificados da Natureza podem contribuir para que estudantes participem de maneira ativa na construção do seu próprio conhecimento. Já em 2002 Medeiros e Medeiros, referindo-se sobre as possibilidades das simulações computacionais, afirmativa que

"Uma grande ênfase é dada comumente ao fato de que novas tecnologias educacionais, tais como as simulações computacionais, possibilitaram uma mudança radical no modo de se ensi-nar a Física. Em muitos aspectos, essa mudança equivale a quebra de um antigo paradigma educacional baseado em aulas expositivas e laboratórios tradicionais." (Medeiros \& Medeiros 2002).

É verdade que uma simulação computacional bem elaborada pode mostrar um fenômeno físico ou processos em geral melhor de que imagens estáticas ou uma fotografia estroboscópica (Medeiros \& Medeiros 2002). Entretanto, é necessário deixar claro para os estudantes que as simulações computacionais, mesmo aquelas produzidas com excelência em termos de qualidade, beleza e realismo, tratam-se de modelos simplificados da realidade, sendo a Natureza muito mais complexa para ser retratada fielmente em softwares. Essas simplificações são pressupostos necessários visto que os programas possuem uma 


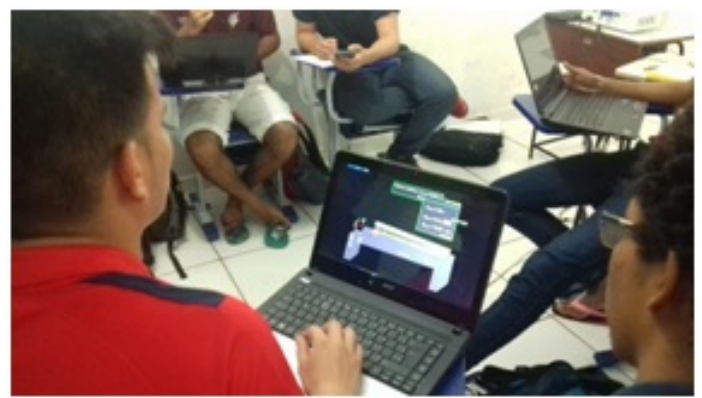

Figura 5: Experimento sobre movimento uniforme estudado com auxílio do computador. (Fonte: Arquivos do autor).

capacidade limitada de simular a realidade e talvez, por esta razão, nunca uma animação poderá conter todas as variáveis que um fenômeno real possui. Porém quando se deseja dar maior ênfase a determinado aspecto do fenômeno físico, essas simplificações constituem aproximações coerentes, principalmente quando se deseja simular um fenômeno no caso ideal em que se despreza a influência de alguns parâmetros. Um exemplo da situação descrita pode ser observado na Figura 5, que simula um movimento uniforme.

Outro aspecto que não pode passar despercebido pelos estudantes é que nenhum compu-tador pensa e menos ainda sabe Física. As leis da Natureza ou do Universo ou da Física estão nas mentes dos programadores que produziram os softwares e, portanto, existe a possibilidade de esses programas conterem erros de Física, ou seja, induzirem os alunos a um entendimento errôneo do fenômeno natural, seja por falta de conhecimento de Física por parte do programador, por limitação da própria linguagem de programação ou talvez falta de perícia na elaboração dos softwares.

Por isso, as simulações computacionais devem ser usadas, analisadas e aplicadas criticamente e, sempre que possível, com a mediação do professor., uma vez que "Uma simulação pode tão somente imitar determinados aspectos da realidade, mas nunca a sua total complexidade. Uma simulação, por isso, nunca pode provar coisa alguma. O experimento real será sempre o último juiz.’(Medeiros \& Medeiros 2002).

\section{O Laboratório Didático Virtual}

É um produto do Mestrado Nacional Profissional em Ensino de Física (MNPEF-SBF) polo 037 UFPA, desenvolvido pelos professores Márcio José Cordeiro de Sena, Antônio Silas de Oliveira Martins, orientados pelo Prof. Dr. Rubens Silva. Esse produto foi elaborado usando o programa Flash CS3 da Macromédia. Ademais, fora constituído, assim, por 12 (doze) experiências de Física a saber: Formas de Trajetória, Movimento Retilíneo Uniforme, Movimento Retilíneo Uniformemente Variado, Aceleração da gravidade - queda livre, Movimento Circun-ferencial Uniforme, Lei de Hooke, Plano horizontal (atrito estático e cinético), Plano inclinado (atrito estático e cinético), Pêndulo Simples, Vasos comunicantes e a lei de Stevin, Teorema de Arquimedes e Densidade, Teorema de Arquimedes e massa específica. Cenas de algumas experiências podem ser vistas nas figuras.

Todas essas experiências virtuais estão acompanhadas com seus respectivos roteiros contendo as questões prévias, objetivos, resumo teórico, Material virtual utilizado, esquema experimental e equação 


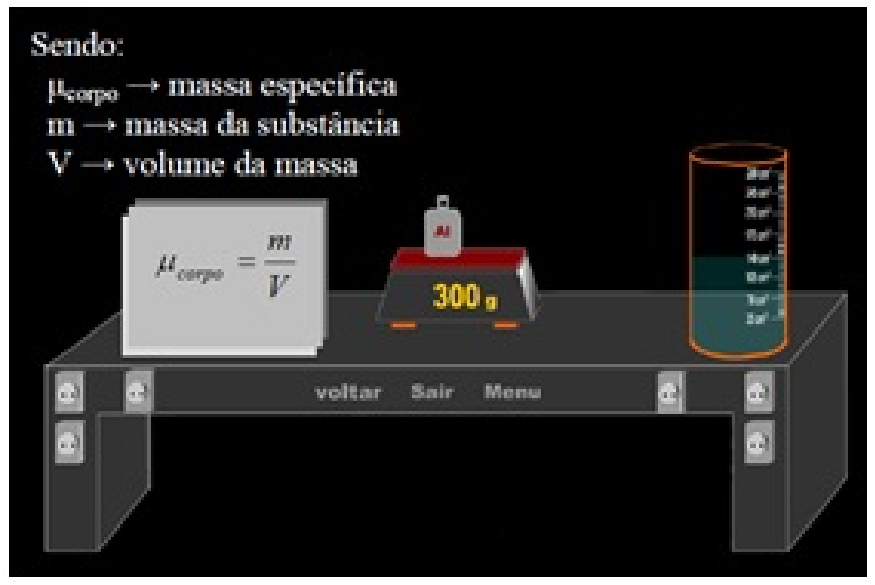

Figura 6: Laboratório didático virtual, experiência sobre o Teorema de Arquimedes. (Fonte: Arquivos do autor).

utilizada, procedimento experimental e problematizações. Na Figura 6, podemos observar a equação e os materiais utilizados.

\section{A Experimentação no Ensino de Física}

Como já foi citado anteriormente o desenvolvimento tecnológico traz grandes benefícios à sociedade e está cada vez mais presente no dia-a-dia das pessoas.

Em meados da década de 80 do século passado, os personagens de um seriado chamado Star Trek comunicavam-se utilizando um aparelho sem a necessidade de fios. Na época, sim-plesmente algo impossível e considerado apenas ficção científica. Entretanto, nos dias de hoje, é muito comum se ver pessoas utilizando celulares para se comunicar. Máquinas que possuem capacidade de processamento tão poderoso quanto de um computador. Sendo assim, por que não inserir essa evolução tecnológica no contexto educacional?

Dentro dessa perspectiva, apresentamos neste trabalho uma proposta que pode contribuir nesse importante processo ensino-aprendizagem: o uso de Softwares como instrumentos de ensino, a fim de envolver o aluno na construção do seu próprio conhecimento, facilitando, assim, sua capacidade de compreensão e associação de conhecimentos, com base na importância da experimentação no Ensino de Física.

\section{Uma Abordagem Vygotskyana}

\subsection{Motivação e Aprendizagem}

Para Gaspar (2014), ancorado pela teoria de Vygotsky, a motivação é a origem do pensamento, podendo assim ser considerada o ponto de partida do processo de aprendizagem baseado em sua teoria. Se para 
aprender é preciso pensar, então podemos concluir que não há aprendizado sem motivação, ou seja, contra a vontade.

Logo, mesmo parecendo evidente a relação motivo-aprendizagem, deve-se atentar, segundo Gaspar (2014), para os tipos de motivação: motivação extrínseca, não apoiada pela teoria de Vygotsky, que se trata de um procedimento que pune ou premia o aluno por recurso alheio ao conteúdo a ser aprendido, como "tirar nota boa na prova"; motivação intrínseca, sugerida por Vygotsky, a qual faz com que o aluno se sinta recompensado cognitivamente pela própria aprendizagem do conteúdo.

Para exemplificar de como pode ser alcançada a indicação pedagógica dessa relação motivo-aprendizagem, utilizaremos a ideia de um corpo com aceleração igual a zero e as consequências que poderiam ser observadas.

De início, o professor deve identificar os conhecimentos prévios, uma noção intuitiva que os alunos possuem em relação ao tema, caso tenham. Neste exemplo, a maioria dos alunos e das pessoas possuem.

Intuitivamente, as pessoas, de modo geral, acreditam que um carro, por exemplo, só pode manter-se em movimento se o motorista estiver pisando no acelerador. Torna-se necessário, então, a aplicação da força do motor do carro constantemente, situação que acaba tornando-se a regra na concepção do aluno. No momento em que é apresentado para o aluno que um foguete tem seus motores desligados em certo momento e que, mesmo assim, continua seu trajeto, esse conhecimento intuitivo é contrariado e obriga o aluno a reformular essa concepção - o que significa, segundo Gaspar (2014), para as teorias de Vygotsky, construir uma nova estrutura de pensamento.

Portanto, é essencial mostrar para o aluno o motivo ou motivos pelos quais é necessário reformular suas preconcepções a respeito do tema escolhido.

\subsection{Zona de Desenvolvimento Proximal (ZDP)}

Outro conceito muito importante e provavelmente mais conhecido da teoria de Vygotsky é a Zona de Desenvolvimento Proximal, ao qual iremos nos referir pela sigla ZDP. O conceito de ZDP seria definido pela distância entre o nível de desenvolvimento atual, relacionado pela capacidade do aluno de resolver um problema sem ajuda, e o nível possível de ser atingido sob a orientação de um adulto ou em colaboração com um aprendiz mais capaz. Portanto, são conhecimentos que a pessoa tem a potencialidade de aprender, mas ainda não com-pletou o processo. Em outras palavras, tratam-se de conhecimentos fora de seu alcance atual, mas potencialmente atingíveis. Ou seja, aquilo que hoje uma criança só consegue fazer com ajuda de alguém, mas que, mais adiante, certamente, fará sozinha (Gaspar, A. 2014).

Em relação à prática pedagógica em sala de aula, o professor deve avaliar o nível cognitivo prévio dos alunos para adequar sua prática pedagógica. No entanto, a ZDP não possui limites tão nítidos. Esses limites são individuais e também estão associados ao conteúdo a ser apresentado, pois cada aluno tem sua ZDP. No entanto, para Vygotsky (2008), o professor não precisa ficar preocupado com a determinação do nível real do desenvolvimento e a ZDP do aluno. Vygotsky defende inclusive a inconveniência da

aplicação de testes de QI (Quociente de Inteligência), pois neles leva-se em conta apenas o nível atual de desenvolvimento mental de um aluno,

"[...] fazendo-a resolver certos problemas padronizados. Supunha-se que os problemas que ela conseguisse resolver sozinha indicavam o nível de desenvolvimento mental nessa 
ocasião específica. Mas, desse modo, só é possível medir a etapa já concluída do desenvolvimento da criança, o que está longe de representar a totalidade do processo". (Vygotsky, L. Pensamento e Linguagem, p. 128.)

A este respeito, inviabilidade acerca da ZDP foi evidenciada quando Vygotsky (2008) relata a experiência com duas crianças de mesma idade mental, 8 anos, propondo-lhes problemas que não conseguiriam resolver sozinhas, mas possíveis de resolver com assistência. Uma delas pôde, com devido auxílio, resolver problemas destinados a uma criança de doze anos, enquanto que a outra não foi além de problemas destinados a crianças de nove anos. A ZDP para a primeira criança é de quatro anos e para a segunda, um ano. Observe que só foi possível determinar essas idades depois do ensino desses conteúdos, e o próprio professor altera a medi-da dessas idades limite ensinando. Dessa forma, testes que avaliam apenas o nível cognitivo real do aluno estão longes de mostrar a capacidade do aluno de aprender conteúdos acima do nível cognitivo real com auxílio de alguém que domine esses conteúdos. (Vygotsky, L. S. 2008)

Por conseguinte, é importante que o professor, ao resolver um novo problema de Física, cuide para que todos os seus alunos possam acompanhar sua resolução, interagindo desde o enunciado até análise e discussão dos resultados. Em seguida, novos problemas semelhantes devem ser sugeridos, sempre tomando cuidado em propor problemas que não ultrapassem a provável ZDP de seus alunos, e a colaboração do professor vai diminuindo gradualmente. Esse processo permite que a mente motivada do aluno construa novas estruturas de pensamento, tornando-o capaz de resolver novos tipos de problemas com o tempo.

Assim sendo, o aluno só pode aprender determinado conteúdo quando lhe ensinarem e lhe derem tempo para desenvolver essas novas estruturas de pensamento. Essas novas estruturas de pensamento não nos são dadas por herança genética e para a construção das mesmas torna-se necessária a colaboração de um parceiro mais capaz. Inicialmente a colaboração em geral ocorre entre as mães e as crianças que aprendem a se comunicar. À medida que as crianças crescem, essa relação deixa de ser única, pois passam a ter contato com outras crianças e outros adultos, aumentando, seta forma, a interação social e ajudando no processo de construção social da mente dos indivíduos.

\subsection{Experimentação orientada pela teoria de Vygotsky}

As teorias de Vygotsky também são válidas na prática experimental independente desta prática ser num laboratório real ou virtual, cabendo ao professor, parceiro mais capaz, elaborar estratégias pedagógicas que possibilitem as interações sociais defendidas pelo mesmo.

A realização de uma atividade experimental necessita da colaboração de alguém que domine o conteúdo e oriente para possibilitar a aprendizagem em todas as etapas que vai desde o objetivo, fundamentos teóricos, montagens, procedimentos experimentais, realizações de medidas, análises de dados e resultados.

Tomaremos, como exemplo, um dos experimentos virtuais deste trabalho: Pêndulo Simples, representado na Figura 7.

Observando a Figura 7, é possível notar ser pouco provável que algum grupo de alunos consiga realizar a experiência e obter todas as informações possíveis sem a colaboração de um professor ou parceiro mais capaz que domine não só a teoria sobre Pêndulo Simples, mas também o procedimento experimental da própria simulação, conforme apresentamos cada passo da experiência de modo resumido em destaque a seguir. 


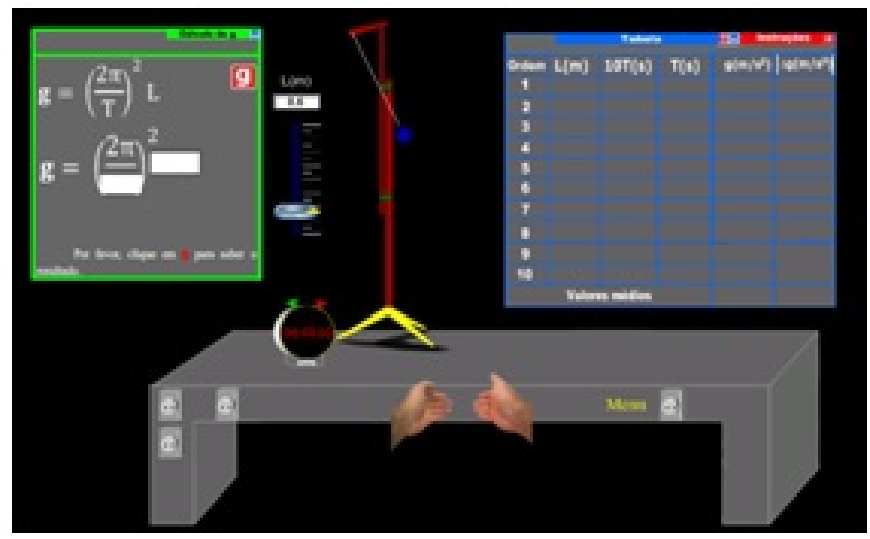

Figura 7: Fotografia da montagem experimental - Pêndulo simples (Fonte: Arquivos do autor).

- Prender o fio na haste e pendurar a massa no mesmo, definir o seu comprimento e, com um leve toque com a mão direita, colocar o pêndulo em movimento;

- Disparar o cronômetro e marcar o tempo de 10 (dez) oscilações, inserindo o valor indicado e o respectivo comprimento do fio na tabela de dados;

- A tabela de dados efetuará o cálculo do período desse movimento, considerando o tempo das 10 oscilações dividido por 10. Esse valor deve ser inserido na equação exibida para e-fetuar o cálculo da aceleração da gravidade;

- Inserir o valor da aceleração da gravidade na tabela de dados e repetir os procedimentos até completar a tabela para obter média, desvio médio e margem de erro do valor encontrado

A colaboração se inicia a partir da montagem do experimento, sendo também necessária para aplicação da expressão matemática que permita alcançar os objetivos do experimento: relacionar o período de oscilação de um pêndulo simples com o comprimento do fio e calcular a gravidade local para confrontar o resultado obtido experimentalmente com o valor teórico. É necessária a apresentação aos alunos da teoria utilizada para obtenção da expressão matemática para que a mesma esteja ao alcance da ZDP da maioria deles, sendo, nesse caso, pouco provável que um aluno sozinho, sem a colaboração do professor, consiga deduzi-la.

Há também a necessidade de orientação para que os alunos possam buscar informações complementares através de um questionário que será respondido pelos mesmos através da interpretação dos dados da tabela por eles preenchida.

A intervenção do professor, então, é essencial para que o aluno conheça o modo como se realiza a prática experimental, proporcionando uma ideia inicial do que é o método científico.

Assim, por mais que o aluno se familiarize com essa prática, tornando-o mais autônomo e diminuindo a colaboração do professor, esta sempre é necessária. A novidade de estar em frente a um computador e realizando um experimento de Física, apesar de proporcionar uma motivação extra, tal motivação deve ser condicionada ao benefício cognitivo desta prática pedagógica e não a algo lúdico ou atrelamento de notas. 


\section{A Importância da Experimentação e o Uso das Tecnologias de Informação e Comunicação (TICs)}

Apesar de diversos estudos apontarem para a importância da experimentação no ensino das ciências, ainda, nos dias de hoje, quase nunca essa prática é utilizada como ferramenta de ensino. Atrelado a isto, observamos as mais variadas "justificativas" para esta subutilização tais como: falta de tempo para organização e aplicação dos experimentos, ausência e custo elevado desses materiais ou ainda riscos na realização de determinados experimentos.

Neste sentido, uma escola que disponibiliza as TICs para seus professores e alunos resolveria quase que a totalidade dessas dificuldades, pois um simples computador, por exemplo, pode conter uma grande quantidade programas de simulações disponíveis na Internet feitos em Java e Flash, uma vez que, segundo Veit \& Teodoro (2002), o computador auxilia na construção do conhecimento e não deve ser apenas utilizado como máquina que apenas transmite informação - como é o caso da quase totalidade das páginas da Internet, apesar da importância de alguns desses materiais.

O computador oferece inúmeras possibilidades de interatividade para combater essa dificuldade no ensino das ciências em geral e em particular no Ensino da Física. Para tanto, torna-se necessária também uma mudança na prática pedagógica do professor em sala de aula, pois apenas a utilização das TICs, sem proporcionar ao aluno reflexão e discussão sobre os conteúdos abordados para proporcionar uma visão crítica, não é suficiente para alcançar esses objetivos, já que:

"[...] as TIC são potencialmente estruturadas de uma educação que pode tornar os estudantes cidadãos mais conscientes, autônomos, ativos e participativos da sociedade contemporânea. A potencialidade modificadora depende da percepção crítica da atualidade e de uma ação transformadora a ser realizada e que depende obviamente da forma como as TIC instauram-se na educação. Assim, afirmamos que a simples inserção das TIC não garante por si essas transformações. São necessárias mudanças significativas no processo de ensino, para que tais objetivos sejam alcançados. Caso contrário apenas iremos reforçar velhas práticas educativas usando as TIC como ferramentas instrumentais mais modernas." (Hohenfeld, D. P. Tese de Doutorado, p. 21.)

Destarte, se os objetivos não tiverem sendo alcançados, a utilização das TICs, no processo de ensinoaprendizagem, pode ser potencializado com o uso de programas de simulação, os quais devem ser escolhidos de acordo com os objetivos do professor na aplicação de um determinado experimento objetivos estes que podem partir de uma demonstração, que o professor prioriza a observação, ou de uma investigação que prioriza maior atuação do estudante sendo esta última o foco deste trabalho.

Nesta perspectiva, de acordo com Veit (2008), a interatividade possui papel importante no processo ensino-aprendizagem. O professor é o mediador durante as aulas, gerando questionamentos para proporcionar a interação entre os alunos sendo essencial a problematização do conhecimento dos estudantes, suas explicações e relações estabelecidas. Isto se justifica porque, por mais que as simulações não representem por completo a realidade, são muito úteis para abordar experiências até mesmo impossíveis de serem aplicadas no contexto escolar por serem demasiadas caras, perigosas, lentas, rápidas, etc. Entretanto, é consenso que a experimentação desempenha um papel importantíssimo no ensino. 
Assim, num mundo em que se observa influência cada vez maior da tecnologia na sociedade, torna-se necessária esta evolução no ensino atrelada à utilização das Tecnologias de Informação e Comunicação.

\section{Laboratório Tradicional e Laboratório Virtual}

Uma escola moderna pode ser provida de dois tipos de laboratórios, os quais podem ser classificados como Laboratório Tradicional (Experimentos Reais) e Laboratório Virtual (Simulações Computacionais). Para Hohenfeld (2013), ambos têm sua praticidade e são interligados de forma teórico-experimental de complementaridade que facilita o processo ensino-aprendizagem durante as aulas de Física.

Nesta perspectiva, os Laboratórios Virtuais são sempre baseados em simulações computacionais devidamente estruturadas e criadas a partir de softwares específicos, buscando aproximar-se o máximo da realidade, proporcionando maior interatividade, aumentando o interesse do aluno diante de uma vivência contínua de sua fase internauta.

Existem diversos softwares, tais como C++, Flash, Algodoo, HTML 5, etc, que são capazes de desenvolver essas simulações na tela de um computador, representando as leis físicas estudadas teoricamente nas salas de aula.

Medeiros \& Medeiros (2002) citam muitos pontos positivos na utilização das simulações virtuais no ensino de Física entre as quais destacamos: concretizar melhor conceitos abstratos, apresentando uma visão simplificada da realidade na seleção dos elementos mais importantes; permitir aos estudantes uma rápida coleta de dados e a geração e testes de hipóteses; bem como uma maior participação do aluno no processo ensino-aprendizagem, tornando a aula mais interativa. Os mesmo autores citam o risco do excesso de entusiasmo acerca da utilização de novas tecnologias, podendo gerar apenas encantamento pelos efeitos computacionais, deixando em segundo plano o benefício cognitivo.

Os Laboratórios Tradicionais são compostos, basicamente, de experimentos específicos para o ensino de ciências que ilustram os conhecimentos obtidos durante as aulas ministradas de modo convencional. As alternativas didático-pedagógicas que podem ser implementadas, com a relação contínua destes dois tipos de laboratórios, agregam valores importantes face ao reconhecimento das práticas educacionais que ajudam a alavancar os conhecimentos adquiridos.

Portanto, no ensino de física, a relação da teoria com a experimentação é de fundamental importância no referendo dos conteúdos aplicados e, nesse contexto, de acordo com Hohenfeld (2013), os laboratórios tradicionais ou reais e os laboratórios virtuais são casados, na presente tecnologia, utilizados de modo específico para uma sociedade cada vez mais antenada com a geração de máquinas com maior capacidade computacional.

\section{Considerações Finais}

Com o avanço das tecnologias relacionadas com interatividade, abre-se grande discussão sobre a forma de como podemos introduzi-las no contexto educacional, em especial no Ensino de Física. Nossas considerações finais, após o desenvolvimento deste trabalho, são pautadas em pontos positivos e negativos que diante da análise críticas dos resultados apresentados mostraram que propostas como esta devem 
estar nos planos dos gestores da educação com o propósito de destacar as alternativas que poderiam mudar o curso normal da educação básica em nosso País. Podemos elencar, positivamente, durante a utilização do laboratório virtual, a possibilidade de sair do plano da imaginação para algo visual, tornando conceitos abstratos mais concretos e proporcionando maior benefício cognitivo ao aluno, bem como ainda as rápidas coletas de dados, que permitem discussão de hipóteses e também maior participação do discente tornando a aula mais interativa e dinâmica, destacando-se como importantes benefícios no processo ensino-aprendizagem. As simulações computacionais utilizadas foram fortemente absorvidas pelos alunos diante da resposta positiva observadas na pesquisa quali-quantitativa realizada e principalmente da complementaridade do conteúdo adquirido nas aulas tradicionais previamente ministradas e sempre motivadas pela interatividade que o laboratório virtual possibilita fazendo uma ligação para os fenômenos físicos reais.

Em contrapartida, há algumas situações decorrentes e alheias, muitas vezes, às vontades individuais, tais como a possibilidade de que haja apenas um encantamento, por parte do aluno, pelos efeitos computacionais, deixando, em segundo plano, o benefício cognitivo que o recurso proporciona. Além disto, destaca-se, também, a ausência de laboratórios de informática em muitas escolas. No entanto, mesmo as que dispõem deste espaço, possuem uma organização física que inviabiliza o maior aproveitamento deste recurso didático.

Neste sentido, em todo país, a maioria das escolas está longe da adequação infra estrutural necessária nas e pelas práticas sociais em que o processo de ensino-aprendizagem se apresenta intra e extramuros.

Logo, o espaço pode ser até multidisciplinar, mas não subutilizado, pois cabe aos gestores, em conjunto com os docentes, mudar o foco metodológico de modo a repensar as práticas educativas a partir de novas tendências pedagógicas, a fim de que possível seja atender ao que aduz a Lei de Diretrizes e Bases da Educação Nacional (1996) quanto ao que propõe, dentre as finalidades, preparar o educando para o mundo do trabalho, das ciências e das tecnologias, de modo a contemplar as novas vertentes da educação contemporânea, em que o uso de recursos modernos, aos poucos, tenta vislumbrar algo inovador no futuro.

Neste contexto, como resposta à pesquisa-ação desenvolvida, observamos que, após a aplicação ou realização das atividades do Laboratório Virtual, comprovamos não só a satisfação com a nova abordagem complementar sobre o assunto ministrado na sala de aula, como o despertar para um novo processo metodológico que requer mudanças qualitativas quando se trata de um processo educacional que exige transformações e adequações tal como definem o Plano Nacional de Educação e as matrizes de referências para o ensino de Física.

Ante o exposto, o presente estudo abre expectativas futuras que vislumbram uma atenção especial da teoria à prática. Assim, entre os itens que se tornaram indispensáveis para alavancar ainda mais a ideia exposta e que podem fazer diferenças significativas na sua aplicação, sugere-se:

- Fazer uma expansão do produto aqui desenvolvido exclusivamente para o $1^{\mathrm{a}}$ ano do Ensino Médio, de modo que atinja as demais séries com as adequações necessárias para as diferentes modalidades da educação básica;

- Dar continuidade oficinas preparatórias para docentes de níveis variados e diferentes instituições que já foram realizadas como um projeto piloto neste trabalho, de modo que intro-duzam o método 
científico e apliquem, em suas aulas, tornando-as mais agradáveis, auxiliando na complementaridade das informações teóricas repassadas;

- Expandir este produto em escala industrial com a produção de CD, com as simulações dos experimentos em programação executável, com gravações em pen drive, impressão dos roteiros que deverão ser disponibilizados a discentes, docentes e críticos da educação, para que se tenha um alcance amplo do conhecimento e dos recursos aqui utilizados.

- Utilizar os avanços dos dispositivos móveis, tais como, celulares e tablets que utilizam sistemas operacionais Android, os quais podem executar as simulações aqui desenvolvidas.

Assim, diante da crise em que se encontra o atual sistema educacional brasileiro, quanto à conjuntura e as tendências pedagógicas vigentes, necessário é repensar as práticas educativas a partir do contexto no qual estamos inseridos como educadores e educandos, a fim de adequarmo-nos à dialética histórica, rompermos paradigmas, bem como ainda aliarmos a teoria à prática a partir de modernas perspectivas de ensino-aprendizagem.

\section{Referências}

[1] BRASIL. 9394/96. Lei de Diretrizes e Bases da Educação Nacional. 1996.

[2] BRASIL. Diretrizes Curriculares Nacionais Gerais da Educação Básica. Brasília: Ministério da Educação, Secretaria de Educação Básica, 2013.

[3] BRASIL. Orientações Curriculares Nacionais para o Ensino Médio. Brasília: Ministério da Educação, Secretaria de Educação Básica, 2006.

[4] BRASIL. Parâmetro Curriculares Nacionais. Brasília: Ministério da Educação, 1999.

[5] CAVAlCANTE, M. A.; BONIZZIA, A.; GOMES, L. C. P.. Aquisição de Dados em Laboratórios de Física: um Método Simples, Fácil e de Baixo Custo para Experimentos em Mecânica. Revista Brasileira de Ensino de Física, v. 30, n. 2, 2501, p. 1-6, 2008.

[6] FIOLHAIS, C.; TRINDADE, J.. Física no Computador: o Computador como uma Ferramenta no Ensino e na Aprendizagem das Ciências Físicas, Revista Brasileira de Ensino de Física, v. 25, n. 3, p. 259-272, 2003.

[7] FREIRE, Paulo. Pedagogia do Oprimido. São Paulo: Paz e Terra, 1993.

[8] HOHENFELD, D. P.. A Natureza Quântica da Luz nos Laboratórios Didáticos Convencionais e Computacionais no ensino Médio. 2013. 146 f. Tese de Doutorado - Instituto de Física, Universidade Federal da Bahia e Universidade Estadual de Feira de Santana, Salvador, 2013.

[9] GASPAR, A.. Atividades Experimentais no Ensino de Física. $1^{\mathrm{a}}$ Ed. São Paulo: Livraria da Física, 2014. 
[10] MACROMEDIA FLASH PROFISSIONAL 8, Aprendizaje de Action Script 2.0 em Flash, $1^{\text {a }}$ Ed.: Septiembre de 2005.

[11] MEDEIROS, A.; MEDEIROS, C. F. de. Possibilidades e Limitações das Simulações Computacionais no ensino de Física. Revista Brasileira de Ensino de Física, v. 24, n. 2, p. 77-86, 2002.

[12] VEIT, E. A.. Modelagem no Ensino / Aprendizagem de Física e os Novos Parâmetros Cur-riculares Nacionais para o Ensino de Física, Revista Brasileira de Ensino de Física, v. 24, n. 2, p. 87-96, 2002.

[13] VIGOTSKI, L. S.. Pensamento e Linguagem. $4^{\text {a }}$ Ed. São Paulo: Martins Fontes, 2008. 